\title{
Refdes Kombinasi Alat Refluks dan Distilasi, Upaya Efisiensi Proses Refluks dan Distilasi untuk Praktikum Kimia Organik
}

\author{
Supaya $^{1}$ \\ ${ }^{1}$ Laboratorium Kimia Organik, Fakultas Matematika Dan IImu Pengetahuan Alam, \\ Universitas Gadjah Mada, Yogyakarta, supaya@ugm.ac.id
}

Submisi: 26 Agustus 2019; Penerimaan 26 September 2019

\begin{abstract}
ABSTRAK
Penyelenggaran praktikum di laboratorium kimia organik selalu menggunakan alat refluks dan destilasi. Untuk mempermudah mahasiswa memasang alat tersebut, laboratorium kimia organik membuat alat yang lebih cepat pemasangannya dan lebih efisien waktu praktikum. Alat tersebut gabungan alat refluks dan destilasi (refdes) untuk mengefisienkan proses refluks dan distilasi tanpa harus bongkar pasang alat.

Proses pengujian alat refdes dengan mengekstrak biji kemiri dan esterifikasi etil asetat. Ekstraksi dan esrifikasi ini dilakukan dengan menggunakan serangkaian alat soxhlet yang diatasnya dipasang alat refdes dengan pendingin spiral. Hasil dari ekstraksi kemudian dibandingkan dengan ekstrak dan esterifikasi dengan alat yang biasa digunakan.

Hasil percobaan di laboratorium kimia organik dengan alat refdes dan evaporator waktu ekstraksi 0,5, 1, dan 1,5 jam diperoleh volume minyak kemiri yang sama yaitu 4, 4,1, dan $5 \mathrm{~mL}$ dengan sisa pelarut $55 \mathrm{~mL}$ pada alat refdes, dan tanpa sisa pelarut pada evaporator. Percobaan esterifikasi etil asetat dengan waktu 30, 45, dan 60 menit, diperoleh volume esterifikasi 44, 40, dan $39 \mathrm{~mL}$ dengan alat refdes, dan 46, 43, $40 \mathrm{~mL}$ dengan distilasi konvensional. Berdasarkan hasil yang diperoleh, penggunaan alat refdes menghasilkan destilat dengan sisa pelarut $60 \%$ dibandingkan dengan evaporasi, sedangkan percobaan esterifikasi hasil destilasi tidak signifikan berbedaannya hanya waktunya lebih cepat dan praktis dalam pemasangan alat refluks dan distilasi.
\end{abstract}

Kata kunci: Alat refluk; distilasi; refdes; minyak kemiri; esterifikasi.

\section{PENDAHULUAN}

Laboratorium Kimia Organik Departemen Kimia FMIPA setiap semester bertugas atau berkewajiban melayani mahasiswa untuk praktikum dan penelitian. Pada semester gasal terdapat satu praktikum yaitu kimia organik I, sedangkan pada semester genap ada dua praktikum yaitu praktikum kimia organik II dan III. Pada praktikum tersebut terdapat mata praktikum yang menggunakan peralatan destilasi dan refluks. Refluks merupakan proses yang harus dilalui agar reaksi yang terjadi dapat berjalan lebih cepat dan sempurna, sehingga diperoleh hasil dengan rendemen yang cukup baik (Purwono dkk., 2013). Umumnya refluks dilakukan pada reaksi yang lambat terbentuk produk. Refluks dilakukan menggunakan seperangkat alat refluks (Gambar 1a). Dua bahan atau lebih yang akan direaksikan biasanya termasuk katalis dan batu didih dimasukkan ke dalam labu alas bulat (leher satu, dua atau tiga tergantung kebutuhan). Labu kemudian disambungkan dengan pendingin bola yang telah disabungkan dengan selang untuk air pendingin. Setelah alat terpasang semua, labu dipanaskan sampai campuran mendidih. Uap pelarut atau uap campuran akan 
naik sampai pendingin bola, dan akan terkondensasi kembali ke dalam labu. Begitu seterusnya sampai beberapa menit atau beberapa jam sampai diperoleh hasil yang diinginkan.

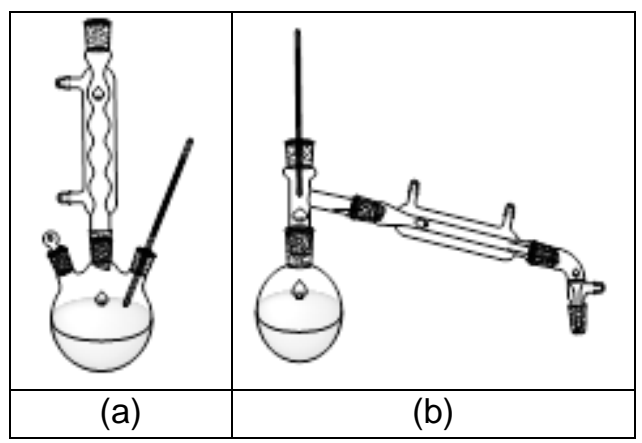

Gambar 1. Seperangkat alat refluks (a) dan seperangkat atat distilasi (b)

Destilasi adalah proses memisahkan campuran dengan dasar perbedaan titik didih. Alat untuk destilasi salah satunya dapat digambarkan pada Gambar 1b. Beberapa macam destilasi yaitu destilasi biasa, destilasi fraksinasi, destilasi vakum dan lain-lain (Vogel ddk.,1996). Pada destilasi biasa (tekanan ruang) campuran dimasukkan pada labu alas bulat yang berisi batu didih, kemudian labu disambung dengan konektor dan pendingin lurus. Ujung pendingin disambungkan dengan konektor yang tersambung ke kolektor berupa labu jantung atau erlenmeyer untuk menampung hasil destilasi.

Untuk mendapatkan produk, tidak jarang proses refluks dan destilasi harus dilakukan secara berurutan. Dari proses tersebut muncul masalah, yaitu prosesnya lama, kurang efisien waktu dan peralatan yang digunakan lebih banyak sehingga kadang terasa ribet. Dari refluks ke proses destilasi mahasiswa harus bongkar pasang alat, sehingga dapat menyebabkan terjadi kecelakaan karena kurang hati-hati atau kurang terampil dalam bongkar dan pasang peralatan gelas yang mudah pecah tersebut. Berdasarkan hal tersebut maka perlu dicari jalan keluarnya, yaitu mendesain alat yang memiliki fungsi dan kemampuan yang sama untuk refluks dan destilasi sekaligus dengan meminimalisir proses bongkar pasang. Hasil diskusi dengan tim muncul ide untuk memodifikasi kedua alat tersebut. Secara sekilas desain alat yang akan dibuat pada kegiatan ini adalah seperti ditampilan pada Gambar 2.

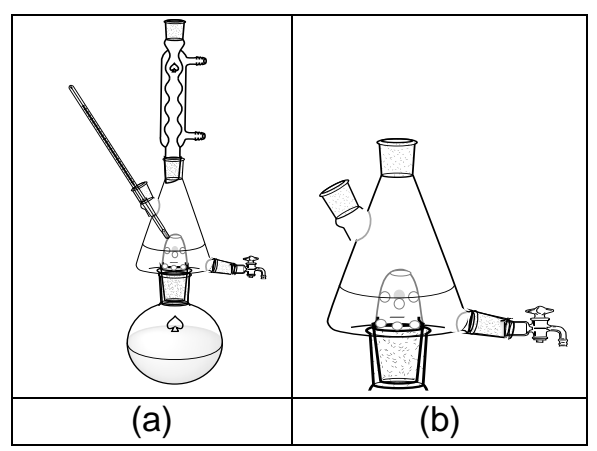

Gambar 2. Draf desain alat refdes, a. satu set alat refdes dan b. konektor khusus (spy konektor).

Gambar di atas merupakan desain awal modifikasi alat refluks dan destilasi yang disebut refdes. Perbedaannya terletak pada konektor khusus yang didesain dan dimodifikasi untuk dapat digunakan sabagai alat refluks sekaligus alat destilasi.

Gambar 3 merupakan desain akhir modifikasi alat refluks dan destilasi yang disebut refdes. Perbedaannya terletak pada konektor khusus yang didesain lebih ramping dan dimodifikasi sabagai alat refluks dapat digukan sekaligus alat destilasi.

Etil asetat merupakan senyawa yang dihasilkan dari pertukaran gugus hidroksil pada asam karboksilat dengan gugus hidrokarbon yang terdapat pada etanol. Etil asetat seringkali disintesis dengan menggunakan katalisator air berupa asam sulfat. Penggunaan katalistor asam sulat dapat menghasilkan konversi yang cukup tinggi 
yaitu dapat mencapai 98\% (Nuryoto, 2008). Pembuatan etil asetat dapat dilakukan dengan esterifikasi fischer yaitu reaksi pembentukan ester dengan cara merefluks sebuah asam karboksilat bersama sebuah alkohol dengan katalis asam (Carey,1993). Selain melalui reaksi di atas, etil asetat juga diprduksi secara komersil melalui reaski antara eilen dan asam asetat.
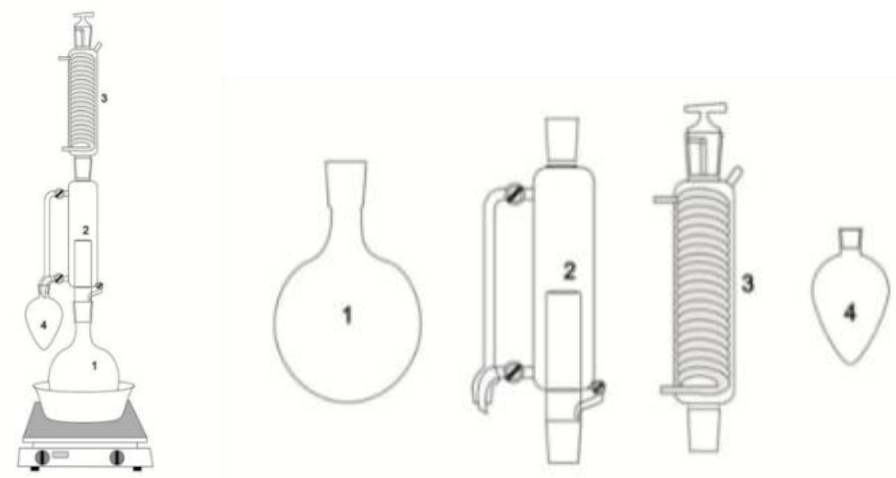

Gambar 3. Draf desain akhir alat refdes, 1. Labu alas bulat, 2. Konektor khusus (spy konektor), 3. pendingin spiral, 4. Labu jantung

Pembuatan etil asetat secara niaga dari asam asetat dan etanol meliputi penyulingan ester bertitik didih rendah (titik didih $=77^{\circ} \mathrm{C}$ ) begitu ester ini terbentuk dari reaksi.Hasil sulingan sebenarnya merupakan azeotron - tiga (suatu campuran yang tetap mendidih pada suhu tetap) mendidih pada suhu $70^{\circ} \mathrm{C}$ dan terdiri atas $83 \%$ etil asetat, $8 \%$ etanol dan air $9 \%$.

Kedua komponen yang disebut terakhir mudah diambil dengan proses ekstraksi, dan etanolnya didaur kembali untuk pengesteran lebih lanjut (Pine, 1988). Ekstraksi merupakan pemisahan suatu komponen dari suatu padatan atau cairan dengan bantuan pelarut. Pemisahan terjadi atas dasar kemampuan larut yang berbeda dari komponen-komponen dalam campuran. Ekstraksi berlangsung secara sistematik pada suhu tertentu dengan menggunakan pelarut (Aziz dkk., 2009).

Berdasarkan bentuk cairan yang diekstraksi, ekstraksi dibedakan menjadi ekstraksi padat cair dan cair-cair. Ekstraksi padat cair adalah transfer difusi komponen terlarut dari padatan inert dalam pelarutnya. Proses ini merupakan proses bersifat fisik karena komponen terlaut kemudian dikembalikan lagi ke dalam semula tanpa mengalami perubahan kimiwai (Sulihono dkk., 2012). Dalam ekstraksi padat cair, larutan yang mengandung komponen harus bersifat tidak larut dengan cairan lainnya. Proses ini banyak digunakan dalam pemisahan minyak dari bahan alam (Ibrahim, 2009).

Kemiri merupakan tanaman yang tingginya mencapai $15-25 \mathrm{~m}$, daunnya berwarna hijau pucat, kacangnya berdiameter $4-6 \mathrm{~cm}$. Biji yang terdapat didalamnya memiliki lapisan pelindung yang sangat keras dan mengandung minyak yang sangat banyak (Arlene, 2010). Minyak kemiri dapat diperoleh melalui proses ekstraksi. Mengekstraksi minyak kemiri dilakukan dengan memisahkan dari cangkang kemudian dikeringkan sampai kadar air $15-20 \%$. Minyak kemiri juga kaya akan lemak essensial omega-3 dan omega-6 (Barus, 2007). 


\section{METODE PENELITIAN}

Bahan yang digunakan untuk membuat rangkaian alat refdas ini adalah gelas kaca Pyrek dan plastik polyetilen. Untuk tarap uji cobanya menggunakan pelarut petroleum eter, biji kemiri dan batu didih.

Proses pengujian alat refdes dengan mengekstrak biji kemiri dan esterifikasi etil asetat yang merupakan mata praktikum kimia organik. Ekstraksi dilakukan dengan menimbang biji kemiri seberat $10 \mathrm{~g}$ dan ditumbuk lembut atau diiris-iris. Biji kemiri kemudian dimasukkan kedalam kedalam kertas saring yang ujung atas dan ujung bawahnya ditutup dengan kapas bebas lemak. Selanjutnya kemiri yang sudah dibungkus dimasukkan kedalam soxhlet. Soxhlet dirangkai dengan labu alas bulat $150 \mathrm{ml}$ yang diberi 5 butir batu didih lalu dimasukkan petroleum eter sebanyak 90 $\mathrm{mL}$. Sedangkan untuk esterifikasi etil asetat sebanyak $20 \mathrm{~mL}$ asam asetat glasial dan $30 \mathrm{ml}$ etanol di masukkan ke dalam labu alas bulat $100 \mathrm{~mL}$. Kemudian ditambahkan asam sulfat $1 \mathrm{~mL}$ dan 4 butir batu didih. Alat refdes kemudian dipasangkan diatas soxhlet yang telah dirangkai dengan pendingin spiral. Sebelum pemanasan dilakukan kran (c) aliran yang menuju ke labu alas bulat dibuka dan kran $(a, b)$ yang menuju ke labu jantung ditutup. Sebelum dirangkai pada leher sohlet, refdes, pendingin, kran-kran diberi vaselin dahulu sebelum digunakan agar tidak terjadi macet (tidak bisa diputar). Labu alas bulat dimasukkan ke penangas minyak dan dilakukan ekstraksi pada suhu $110^{\circ} \mathrm{C}$ selama 0,5 jam, 1 jam, 1,5 jam. Jumlah siklus yang terjadi selama proses ekstraksi dihitung. Setelah ekstraksi selesai destilasi langsung dilakukan dengan membuka kran (a), (b) dan kran (c) ditutup.
Panaskan lagi sampai suhu refluks, petroleum eter yang menguap akan didinginkan oleh pendingin spiral dan akan mengalir ke labu jantung sampai semua pelarut habis. Sisa pelarut yang ada pada labu bisa dihilangkan dengan vacuum minyak atau air, dengan cara menutup kran $(a, b)$ dan membuka kran (c) seperti pada waktu ekstraksi soxlet. Sambungkan slang vacuum dengan kran yang ada di ujung pendingin dan hidupkan pompa vacuum maka sisa pelarut akan kesedot masuk ke pompa vacuum. Hasil dari ekstraksi minyak biji kemiri dan esterifikasi etil asetat diukur, ditimbang dan dibandingkan dengan hasil praktikum yang menggunakan alat sebelumnya.

\section{HASIL DAN PEMBAHASAN}

Alat refluks dan distilasi sangat berbeda sehingga untuk proses refluks dan distilasi perlu dua alat yang berbeda dan dua langkah kerja yang berbeda, dengan begitu perlu waktu dan energi (proses pemanasan) yang lebih banyak dari dua proses tersebut sehingga kurang efektif. Persamaan dari kedua proses tersebut yaitu adanya proses pemanasan, sehingga pelarut atau komponen campuran dengan titik didih lebih rendah akan menguap dan dilanjutkan proses kondensasi. Hasil ekstraksi soxhlet yang telah dilakukan kemudian di evaporasi, sehingga pelarut yang digunakan akan habis semuanya menguap masuk ke vacuum air yang ada di evaporator.

Untuk mempercepat waktu praktikum laboratorium kimia organik mencoba membuat alat yang lebih praktis dan lebih cepat waktu pemasangannya yaitu refdes. Cara pemasangan alat tersebut cukup mudah bagi mahasiswa yang praktikum, karena hanya memasang ditengah antara labu dan pendingin bola atau pendingin spiral. 
Penggujian alat refdes untuk mendapatkan hasil yang dinginkan, laboratorium merancang beberapa kali sehingga diperoleh desain yang lebih efisien. Desain tersebut telah dicoba di laboratorium kimia organik pada praktikum ekstraksi padat cair dan esterifikasi etil asetat. Hasil ekstraksi berupa minyak berwarna coklat bening sedangkan produk esterifikasi berupa cairan bening dengan bau khas ester. Dari percobaan tersebut didapatkan hasil minyak kemiri seperti yang ditunjukkan pada Tabel 1.

Tabel 1. Hasil ekstraksi biji kemiri dengan alat refdes

\begin{tabular}{cccc}
\hline $\begin{array}{c}\text { Waktu } \\
\text { (jam) }\end{array}$ & $\begin{array}{c}\text { Volume } \\
\text { Minyak } \\
(\mathrm{mL})\end{array}$ & $\begin{array}{c}\text { Berat } \\
\text { Minyak } \\
(\mathrm{g})\end{array}$ & $\begin{array}{c}\text { Volume } \\
\text { Sisa } \\
\text { Pelarut } \\
(\mathrm{mL})\end{array}$ \\
\hline 0,5 & 4,0 & 3,16 & 55 \\
1,0 & 4,1 & 3,41 & 55 \\
1,5 & 5,0 & 4,03 & 55 \\
\hline
\end{tabular}

Tabel 2. Hasil ekstraksi biji kemiri dengan alat evaporator

\begin{tabular}{cccc}
\hline $\begin{array}{c}\text { Waktu } \\
\text { (jam) }\end{array}$ & $\begin{array}{c}\text { Volume } \\
\text { Minyak } \\
(\mathrm{mL})\end{array}$ & $\begin{array}{c}\text { Berat } \\
\text { Minyak } \\
(\mathrm{g})\end{array}$ & $\begin{array}{c}\text { Volume } \\
\text { Sisa } \\
\text { Pelarut } \\
(\mathrm{mL})\end{array}$ \\
\hline 0.5 & 4,0 & 3,16 & 0 \\
1,0 & 4,0 & 3,18 & 0 \\
1.5 & 5,0 & 4,03 & 0 \\
\hline
\end{tabular}

Tabel 3. Hasil esterifikasi etil asetat dengan alat refdes

\begin{tabular}{ccc}
\hline $\begin{array}{c}\text { Waktu } \\
\text { (menit) }\end{array}$ & $\begin{array}{c}\text { Volume } \\
\text { Ester }(\mathrm{mL})\end{array}$ & $\begin{array}{c}\text { Berat Ester } \\
(\mathrm{g})\end{array}$ \\
\hline 30 & 44 & 37,80 \\
45 & 40 & 35,40 \\
60 & 39 & 35,01 \\
\hline
\end{tabular}

Tabel 4. Hasil esterifikasi etil asetat dengan alat konvensional

\begin{tabular}{ccc}
\hline $\begin{array}{c}\text { Waktu } \\
\text { (menit) }\end{array}$ & $\begin{array}{c}\text { Volume } \\
\text { Ester }(\mathrm{mL})\end{array}$ & $\begin{array}{c}\text { Berat Ester } \\
(\mathrm{g})\end{array}$ \\
\hline 30 & 46 & 38,30 \\
45 & 43 & 36,00 \\
60 & 40 & 35,02 \\
\hline
\end{tabular}

Dari hasil percobaan dengan alat refdes pada percobaan ekstraksi soxlet pelarut yang tersisa $55 \mathrm{~mL} / 90 \times 100 \%=$ $270 \mathrm{~mL}$, bisa menghemat $60 \%$. Selama seminggu ada 2 hari praktikum, dan setiap hari ada 3 kelompok praktikum, sehingga selama satu semester total pelarut petroleum eter yang digunakan $270 \mathrm{~mL} \times 12$ × $2=6.480 \mathrm{~mL}$. Dengan penghematan $60 \%$ maka sisa pelarut yang masih bisa digunakan $60 \% \times 6.480$ $\mathrm{mL}=3.888 \mathrm{~mL}$, serta waktu yang digunakan lebih efisien karena tidak ada antrian disebabkan keterbatasan alat evaporator yang harganya cukup mahal.

Hasil yang diperoleh pada percobaan esterifikasi etil asetat penggunaan alat refdes membutuhkan waktu yang lebih singkat karena tidak perlu bongkar pasang alat refluks dan destilasi, dibandingkan dengan alat refluks dan distilasi konvensional. Hasil percobaan dengan alat sebelumnya ditunjukkan pada Tabel 3. dan Tabel 4..

\section{KESIMPULAN}

Berdasarkan hasil percobaan dan pembahasan dapat disimpulkan bahwa pembuatan alat refdes pada paraktikum di laboratorium kimia organik dapat mempersingkat waktu praktikum, meminimalkan kecelakaan di laboratorium terutama peralatan gelas yang pecah atau retak, dan pemanfatan sisa pelarut yang digunakan bisa untuk praktikum selanjutnya sehingga biaya praktikum bisa dikurangi dibandingkan dengan evaporator vacuum buchi yang pelarut petroleum eter semua hilang masuk vacuum minyak/air.

\section{DAFTAR PUSTAKA}

Arlene, A., 2010, Ekstraksi Kemiri dengan Metode Soxhlet dan Karaktrisasi Minyak Kemiri, Jurnal Teknik Kimia, 2 (2), 1-5. 
Aziz, T., Cindo, R. K. M., dan Fresca, A., 2009, Pengaruh Pelarut Heksana dan Etanol, Volume Pelarut, dan Waktu Ekstraksi terhadap Hasil Ekstraksi Minyak Kopi, J. Tek. Kim., 1(16), 1-8.

Barus, P., 2007, Interesterifikasi Stearin Sawit dengan Minyak Kemiri menjadi Pengganti Lemak Margarin, Jurnal Penelitian MIPA, 1, 1-7.

Carey, F., 1993, Advanced Organic Chemistry Part B: Reaction a Syntesis, Plenum Press, London.

Ibrahim., 2009, Ekstraksi, Sekolah Farmasi ITB, Bandung.

Nuryoto., 2008, Studi Kinerja Katalisator Lewatit Monoplus S-100 pada Reaksi Esterifikasi antara Etanol dan Asam Asetat, Jurnal rekayasa proses, 2 (1), 24.

Pine., 1998, Kimia Organik II, ITB, Bandung.

Purwono, B., Pranowo, D., Matsjeh, S., Wahyuningsih, T.D., dan Haryadi, W., 2013, Petunjuk Praktikum Kimia Organik III, Dep. Kimia, FMIPA UGM.

Sulihono, A., Tarihoran, B., dan Agustina, T.E., 2012, Pengaruh Waktu, Temperatur, dan Jenis Pelarut Terhadap Ekstraksi Pektin dari Kulit Jeruk Bali (Citrus maxima), Jurnal Teknik Kimia, 4 (18), 1-8.

Vogel, A.I., Tatchell, A.R., Furnis, B.S., Hannaford, A.J., dan Smith, P.W.G., 1996, Vogel's Textbook of Practical Organic Chemistry, $5^{\text {th }}$ Ed., Pearson Education Limited, London 